\title{
DEPRESSION AND SUICIDALITY DURING PREGNANCY
}

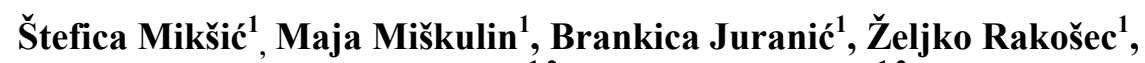 \\ Aleksandar Včev ${ }^{1,2}$ \& Dunja Degmečić ${ }^{1,2}$ \\ ${ }^{1}$ Faculty of Medicine, University Josip Juraj Strossmayer, Osijek, Croatia \\ ${ }^{2}$ University Hospital Osijek, Josipa Huttlera 4, Osijek, Croatia
}

received: 1.9.2017;

revised: 17.10.2017;

accepted: 12.11 .2017

\section{SUMMARY}

Background: Pregnant women experience a set of biological and psychological disturbances. The aim of this study was to assess the appearance of depressive symptoms and suicidal thoughts in pregnant women during the third trimester of pregnancy.

Subjects and methods: A total of 110 pregnant women were included in the study. All of them filled out an anonymous questionnaire about sociodemographic data, Edinburgh Postnatal Depression Scale (EPDS), Beck Depression Inventory (BDI), and Beck Anxiety Inventory (BAI).

Results: Study participants were between 18-46 years of age. 45.45\% of the pregnant women were between 37 and 39 weeks pregnant. According to the EPDS, the risk for perinatal depression was observed in 29 (23.36\%) pregnant women: 15 (13.64\%) of them had a total score on EPDS from 10-12, and 14 (12.72\%) had a total score of 13-20. A higher score on both Beck scales was characteristic for pregnant women with a higher risk for the development of perinatal depression based on the results on EPDS. The prevalence of suicidal thoughts was $2.73 \%$.

Conclusions: Perinatal depression is a state which should be given more attention. The recognition of perinatal depression during pregnancy allows health medical workers to observe pregnant women at risk and then to make preventive and clinical interventions. The risk for perinatal depression is higher in pregnant women with more expressed depressive and anxiety symptoms. Pregnant women with suicidal thoughts are more anxious and depressed.

Key words: pregnancy - perinatal depression - suicidality

$* * * * *$

\section{INTRODUCTION}

Pregnancy is a state of higher sensitivity for women; it is not a time of emotional stability as thought in the past, but a time of great biological and psychological changes (Degmecic 2014). Mental disorders in pregnancy have more prevalence than preeclampsia, preterm childbirth or gestational diabetes (Gluckman et al. 2008). Perinatal depression often remains unrecognised by the health care workers, but its early detection and treatment may prevent the development of postpartum depression. One of the reasons why it remains unrecognised may be because depressive symptoms can resemble pregnancy symptoms which may include sleep disturbances, fluctuations in appetite, loss of energy, tiredness, and libido changes (Clark 2000). Mood changes in pregnancy are among stronger predictors for the development of postpartum depression and they represent risk for the mother as well as for the child (Jakovljević 2004, Zubaran et al. 2010). Different factors influence pregnant women's mental health, such as marital relationships and relationships within family, economic situation, planned or unplanned pregnancy, and most of all unwanted pregnancy (Gluckman et al. 2008). Literature data shows that two thirds of pregnant women in the first and third trimester of pregnancy manifest psychological symptoms such as anxiety, irritability, and lability in mood. The depression rate grows in the third trimester (Gluckman et al. 2008). The prevalence of depressive disorders in pregnancy is around 10\%-36\% (Park et al. 2015). Suicidal thoughts in pregnant women are connected with the age of pregnant women (the older the woman, the higher risk of suicidal thoughts), inadequate life conditions, greater number of children, and lower economic status (Fonesca-Machado et al. 2015).

In May 2015, the American Congress of Obstetricians and Gynaecologists (ACOG) published recommendations for screening for perinatal depression according to which the screening for perinatal depression and anxiety symptoms should be conducted at least once during the perinatal period (using standardised and validated instruments). The screening should be conducted by obstetric and gynaecological professionals who, in turn, should include other specialists if necessary. The recommendations also state that women with perinatal mood disturbances, depression, anxiety, and risk factors need more continuous supervision and treatment methods, and that the screening for mood disorders in pregnancy should be conducted with the Edinburgh Postnatal Depression Scale (EPDS).

The aim of this study was to assess the appearance of depressive symptoms and suicidal thoughts in pregnant women during their third trimester of pregnancy using the Edinburgh Postnatal Depression Scale - EPDS (Cox et al. 1987, Kozinsky et al. 2015), Beck Depression Inventory - BDI (Beck et al. 1961, Beck et al. 1996) and Beck Anxiety Inventory - BAI (Beck et al. 1988, Beck et al. 1993). 


\section{SUBJECTS AND METHODS}

Study design was cross-sectional among the population of pregnant women in primary gynaecological care setting in Đakovo from April till August year 2015. Three outpatient gynaecological units in primary care setting in Đakovo were included in the study. Inclusion criteria were as follows: physically healthy pregnant women in the third trimester of pregnancy without psychiatric history. Exclusion criteria were: mood disorders during and after earlier pregnancies, preeclampsia and eclampsia, gestational diabetes, chronic somatic disorders.

The study was designed in such a way that every second pregnant woman in the third trimester of pregnancy who came to one of those three outpatient primary care settings was included in the study. One of the pregnant women refused to participate in the study, and five of them did not meet the inclusion criteria. The study was approved by the Ethical Committee of the Faculty of Medicine in Osijek and also by the Ethical Committee in Dom zdravlja (Public Health Care Institution) Đakovo where the field research was conducted. All of the participants signed informed consent and patient anonymity is preserved. All of the participants filled out a sociodemographic questionnaire which was custom-developed for this study by the researchers and which consisted of ten questions about the participants' age, marital status, place of living, employment, education, number of previous pregnancies and possible pregnancy complications, questions about this pregnancy, and personal habits. The participants also filled out Edinburgh Postnatal Depression Scale (EPDS), Beck Depression Inventory (BDI) and Beck Anxiety Inventory (BAI). All of the scales were in Croatian language.

In statistical analysis categorical data are shown with absolute and relative frequencies and differences in categorical variables were tested with Chi-2 test. Deviations from normal distribution of variables were tested with Mann-Whitney test. Internal consistency of the used scales was measured with Chronbach's Alpha coefficient. Differences between groups in observed characteristics were tested with nonparametric sum of ranges, and their correlation was measured with Spearman correlation test $\left(\mathrm{r}_{\mathrm{s}}\right)$. The level of significance was 0.05. Statistical program SPSS (16.0, SPSS Inc, Chicago, IL, USA) was used for statistical analysis.

\section{RESULTS}

The study population consisted of 110 pregnant women aged between 18 and 46 . The mean value was 28.09 years $(\mathrm{SD}=5.24) .45 .45 \%$ of the pregnant women were 37-39 weeks pregnant. Most of the pregnant women were married $(\mathrm{N}=108,98.2 \%)$, two of them lived with their unmarried partners. 62 of them $(56.4 \%)$ lived with their family, husband and children, and
19.1\% lived with wider family. Most of the respondents had high school diploma as their highest qualification $(\mathrm{N}=76,69.1 \%)$, around $15 \%$ of the respondents had a university degree $(\mathrm{N}=17,15.5 \%)$, while a small number of respondents had elementary school diploma $(\mathrm{N}=10$, $9.1 \%)$ or a college degree $(\mathrm{N}=6,5.5 \%)$ as their highest qualification. According to the results on the EDPS, the authors observed that in a predominant number of participating pregnant women there was no present risk of perinatal depression as the results of the total score were lower than 10 in $73.64 \%$ of the study population. However, in a bit over a quarter of pregnant women $(26.36 \%)$ the risk of perinatal depression was detected. This group was divided into two categories: those with a total score results of $10-12(\mathrm{~N}=15 ; 13.64 \%)$, and those with the total score higher than $13(\mathrm{~N}=14 ; 12.72)$ which represents a stronger indication of the potential risk of perinatal depression. As can be seen, among the participants with a higher risk of perinatal depression (a quarter of the total study population), almost a half of them exhibited results which point to a high risk for the development of perinatal depression $(12.72 \%)$.

EDPS scale is characterised by a special emphasis on the claim indicating existence of suicidal thoughts, and it includes thoughts about doing harm to yourself or the baby. The authors of the paper observed frequencies of all possible answers relating to this claim. The results showed us that among the study population of pregnant women not one of them had frequent suicidal thoughts. Almost all of the studied pregnant women $(\mathrm{N}=107$; $97.27 \%$ ) answered that they never had suicidal thoughts, and just three of them have rarely had suicidal thoughts $(2.73 \%)$. The analysis of total score on the EPDS for the three pregnant women with suicidal thoughts showed that the two of them were in the risk group for the development of the perinatal depression whereas one had a border total EPDS score. The authors also used BDI for the screening of the depression and BAI for the screening of the anxiety symptoms. Furthermore, the authors compared results on the EDPS scale and BDI scale for the depressive symptoms in the study population. Also, the authors compared the characteristics of women in the two groups based on the results of the EDPS scale: the first group of pregnant women who were at risk for the development of depression $(\mathrm{N}=29)$ and the other group of pregnant women without that risk $(\mathrm{N}=81)$.

The reliability of inner consistency (Cronbach $\alpha$ ) of Beck depression inventory $(\alpha=0.794)$ and Beck anxiety inventory $(\alpha=0.883)$ is adequately high, which implies the reliability of the scale. Considering the distribution of the results on the EDPS scale as well as on the BDI and BAI scales, the results deviated with statistical significance from the normal distribution. The difference in depressive and anxiety symptoms in pregnant women without risk and those with the expressed risk for perinatal depression was tested with nonparametric test of cumulation of ranks (Mann-Whitney U-test) (Table 1). 
Table1. Differences between groups of pregnant women considering depressive and anxiety symptoms accoording the BDI and BAI

\begin{tabular}{|c|c|c|c|c|}
\hline & & MR & $\mathrm{TR}$ & Z \\
\hline \multirow{2}{*}{ Beck depression innventory } & WRPD & 43.78 & 3546.50 & \multirow{2}{*}{$-6.478 *$} \\
\hline & PRD & 88.22 & 2558.50 & \\
\hline \multirow{2}{*}{ Beck anxiety inventory } & WRPD & 44.25 & 3540.00 & \multirow{2}{*}{$-5.912 *$} \\
\hline & PRD & 84.66 & 2455.00 & \\
\hline
\end{tabular}

$* \mathrm{p}=0.00 ;(\mathrm{p}<0.05) ; \mathrm{MR}-$ medium range; TR - total of ranges; $\mathrm{Z}$ - Mann-Whitney U test;

WRPD - Pregnant women without risk for perinatal depression (EPDS total score lower than 10);

RPD - Pregnant women with risk for perinatal depression (EPDS total score 10 and higher)

Table 2. Correlation of perinatal depression (EPDS), depression (BDI) and anxiety (BAI) in our groups of pregnant women

\begin{tabular}{lcc}
\hline Spearman's $\mathrm{r}_{\mathrm{s}}$ & Depression (BDI) & Anxiety (BAI) \\
\hline Perinatal depression (EPDS) & $0.662^{* *}$ & $0.634^{* *}$ \\
Depression (BDI) & - & $0.723^{* *}$ \\
\hline
\end{tabular}

$* * \mathrm{p}<0.01$

Table 3. Analysis of some characteristics of pregnant women with and without risk for perinatal depression according to the total score on EPDS

\begin{tabular}{|c|c|c|c|c|c|c|}
\hline & & WRPD (N) & $\mathrm{RPD}(\mathrm{N})$ & $\chi^{2}$ & df & Significance $(\mathrm{p}<0.05)$ \\
\hline \multirow{3}{*}{ Pregnancy } & First & 24 & 10 & \multirow{3}{*}{0.303} & \multirow{3}{*}{2} & \multirow{3}{*}{0.859} \\
\hline & Second & 28 & 10 & & & \\
\hline & Third and more & 29 & 9 & & & \\
\hline \multirow{2}{*}{ Working status } & Employed & 38 & 11 & \multirow{2}{*}{0.830} & \multirow{2}{*}{1} & \multirow{2}{*}{0.362} \\
\hline & Unemployed & 41 & 18 & & & \\
\hline \multirow{2}{*}{$\begin{array}{l}\text { Spontaneous miscarridge } \\
\text { in earlier pregnancy }\end{array}$} & Yes & 20 & 7 & \multirow{2}{*}{0.001} & \multirow{2}{*}{1} & \multirow{2}{*}{0.974} \\
\hline & No & 61 & 22 & & & \\
\hline \multirow{2}{*}{$\begin{array}{l}\text { Complications } \\
\text { in earlier pregnancies }\end{array}$} & Yes & 14 & 6 & \multirow{2}{*}{0.239} & \multirow{2}{*}{1} & \multirow{2}{*}{0.625} \\
\hline & No & 67 & 23 & & & \\
\hline \multirow{2}{*}{$\begin{array}{l}\text { Recomended resting } \\
\text { durig pregnancy }\end{array}$} & Yes & 15 & 5 & \multirow{2}{*}{0.023} & \multirow{2}{*}{1} & \multirow{2}{*}{0.878} \\
\hline & No & 66 & 24 & & & \\
\hline Attending the pregnancy course & Yes & 19 & 7 & 0.005 & 1 & 0.941 \\
\hline
\end{tabular}

WRPD - Pregnant women without risk for perinatal depression (EPDS total score lower than 10);

RPD - Pregnant women with risk for perinatal depression (EPDS total score 10 and higher)

The results showed that depression and anxiety in pregnant women with expressed risk for perinatal depression differs from the depression and anxiety of pregnant women without the risk for perinatal depression. In other words, pregnant women with the risk for the development of the perinatal depression were in average more depressed $(Z=-6.478, p<0.001)$ and anxious $(Z=-5.912, p<0.001)$ from the pregnant women who have not shown the risk for the development of the perinatal depression.

This relation can be expressed by means of correlation coefficient. Due to the above mentioned reasons connected with the type of distribution, the authors calculated nonparametric correlation coefficient Spearman Rho $\left(r_{s}\right)$ in order to get an insight into the correlation of the observed characteristics (Table 2).

As we can see from the correlation coefficient, the mutual correlation of perinatal depression and anxiety was statistically significant and positive. In other words, the risk for perinatal depression was on average higher, and respectively grew as the depression $\left(r_{s}=0.662\right.$, $\mathrm{p}<0.05)$ and anxiety $\left(\mathrm{r}_{\mathrm{s}}=0.634, \mathrm{p}<0.05\right)$ were more expressed. It is also clear that the same pattern occurred with depression and anxiety: with higher levels of anxiety there were also higher levels of depression $\left(\mathrm{r}_{\mathrm{s}}=0.723, \mathrm{p}<0.05\right)$.

The authors also analysed whether these two groups of pregnant women - one with the risk for perinatal depression and the other without the risk - differ in other characteristics. Non parametric statistic method Spearman correlation coefficient was used $\left(r_{s}\right)$ in the analysis of the week of gestation and risk for perinatal depression and the results showed that there was no statistically significant correlation $\left(\mathrm{r}_{\mathrm{s}}=0.5, \mathrm{p}>0.05\right)$, suggesting that risk for perinatal depression does not depend on the week of gestation.

Table 3. shows both the characteristics of the pregnant women and the characteristics of their pregnancy in relation to the risk for perinatal depression. Chi 2 test was used for statistical analysis. There was no statistical significance between the perinatal depression and the fact whether this was a woman's first, second, third or any other subsequent pregnancy $\left(\chi^{2}=0.303, p>0.05\right)$. Also there was no difference between two groups concerning the employment status $\left(\chi^{2}=0.830, p>0.05\right)$. Spontaneous miscarriage in the previous pregnancy 
exhibited no connection with the risk for perinatal depression $\left(\chi^{2}=0.001, p>0.05\right)$, and neither did the complications in earlier pregnancies $\left(\chi^{2}=0.239, p>0.05\right)$. The results also showed that women in both groups rested equally and in accordance with the recommendations for pregnant women $\left(\chi^{2}=0.023, p>0.05\right)$, and that there was no difference between two groups in attending the course for pregnant women $\left(\chi^{2}=0.005, \mathrm{p}>0.05\right)$.

\section{DISCUSSION}

Depression, one of the frequently seen health problems among women, is experienced by women in fecundity periods and its incidence increases with pregnancy. Literature data shows that symptoms of depression are more intense in the first trimester, their intensity decreases in the second trimester, and in the third trimester the percentage of depression rises (Fazlagić 2011, Glavin et al. 2010, Park et al. 2015).

In studies that investigated the rates of depression in different cultures, the rate of depression during pregnancy was found to be $7.5 \%$ in China, $17.9 \%$ in Hungary, $30 \%$ in Canada, $19.6 \%$ in the USA and $19.6 \%$ in Brazil, whereas in Turkey it ranges from $12 \%$ to $36 \%$ (Aktas et al. 2015). According to Park et al. (2015) the prevalence of depression in the prenatal and postpartum period in Korean women ranged from $40.5 \%$ to $61.4 \%$. The prevalence of prenatal depression was highest in the third trimester. In other words, the specific period of gestation was a significant factor in prenatal depression. Stress (the burden of delivery) was significantly correlated to depression or depressive symptoms (Slade et al. 2010). Our study included 110 healthy pregnant women in the third trimester of pregnancy. $23.36 \%$ of them exhibited risk for development of perinatal depression according to the EPDS score, and $12.72 \%$ of pregnant women had EPDS score which indicates a higher risk for perinatal depression. Nakić-Radoš et al. (2016) in a prospective study conducted in Croatia followed women from the third trimester of pregnancy through their early postpartum period, and concluded that symptoms of postpartum depression could be equally predicted by perinatal depressive symptoms $(30.3 \%)$ and the early postpartum period (34.0\%). A study done by Olivier et al. (2015) shows that prevalence for depression in pregnant women is about $10 \%$ in high-income countries, but, for example, in Sweden this percentage may be as high as $20 \%$. As we can see, the range of prevalence of depression in pregnancy is wide and our results are in concordance with this.

Glavin et al. (2010) describe that prevalence of perinatal depression may vary from $4.4 \%$ to $73.7 \%$. This research describes the relationship between gestational week and the risk for the occurrence of perinatal depression, and there was no statistical significance. The results in our study also had no statistical significance between the appearance of depressive symptoms and gestational week, suggesting that the risk for perinatal depression is not dependent of gestational week.
Besides the weeks of gestation, our study also analysed the connection between the risk for perinatal depression and some other factor, such as the number of previous pregnancies, marital status, employment, complications in previous pregnancies or spontaneous miscarriages, and none of these factors showed any statistical significance.

For example, in a study done by Actas et al. (2015) the education level of pregnant women and their husbands as well as the employment status of pregnant women were detected as factors that increased the severity of depression symptoms. Similarly, Bodecs et al. (2009), Bundevicius et al. (2009) and Lancaster et al. (2010) noted that pregnancy depression was seen more among pregnant women who had low education level and worked at a job with an unsatisfactory income. This was not supported in our study.

A study done by Dmitrović-Kitanović et al. (2014) showed that $21 \%$ of the sample of pregnant women in Serbia was screened as depression positive during pregnancy. Risk factors were found to be low education level, low satisfaction with financial situation, and highrisk pregnancy. It is interesting to mention that according to the study of Varela et al. (2015), in clinical practice, pregnant women who suffer from low levels of prenatal depressive and anxiety symptoms may be reassured, in respect of the adverse outcomes of these mood symptoms on the neonate.

Our study also analysed the very important topic of suicidal ideation in pregnancy. Suicidality during the perinatal period is a serious public health concern, because suicide is among the leading causes of maternal mortality (Lindahl et al. 2005). The prevalence of suicidal ideation in pregnant women more than doubled from 2006 to 2012 in the USA, whereas prevalence of suicide and self-inflicted injury remained stable (Zhong et al. 2015). The results from our study showed low risk for suicide ideation in our studied population: the prevalence for suicidal ideation was $2.73 \%$. FonescaMachado et al. (2015) showed in their study that the prevalence of indicators of suicidal ideation in pregnant women was $7.8 \%$. Among perinatal women screened for depression, $3.8 \%$ reported suicidal ideation, but only $1.1 \%$ of this subgroup was at a high risk for suicide in a study done by Kim et al. (2015). Because few studies have examined the maternal experiences and beliefs associated with perinatal suicidal ideation, further research is needed to identify beliefs and experiences related to perinatal suicidal ideation to assist health professionals in screening and treating perinatal women.

\section{CONCLUSION}

Perinatal depression is a state which should be given more serious consideration. In everyday clinical practice instruments should be introduced for the early identification of pregnant women with a higher risk for depression development. Recognition of depression during pregnancy allows health care workers to follow 
up pregnant woman who are at risk for depression, then to conduct preventive strategies and, with clinical interventions, set diagnosis of perinatal depression (Choi et al. 2014). Early intervention and treatment of perinatal depression can prevent the appearance of postpartum depression. The results have shown that there is a good positive correlation between the assessment of the perinatal depression and Beck depression inventory $\left(\mathrm{r}_{\mathrm{s}=}=0.662, \mathrm{p}<0.05\right)$ and Beck anxiety inventory $\left(\mathrm{r}_{\mathrm{s}}=0.634, \mathrm{p}<0.05\right)$. The risk of perinatal depression is higher in women with more pronounced depressive and anxiety symptoms. Pregnant women who exhibit more anxiety and depressive symptoms may have suicidal thoughts and according to that they should be followed up with more intensity.

\section{Acknowledgements: None.}

\section{Conflict of interest: None to declare.}

\section{Contribution of individual authors:}

Štefica Mikšić: participated in acquisition of data, conception and design of the study, in drafting of the article;

Maja Miškulin: participated in conception and design of the study and in statistical expertise and analysis and interpretation of the data as well as in critical revision;

Brankica Juranić: participated in acquisition of the data and in administrative, technical and logistic support;

Željko Rakošec: participated in statistical expertise and analysis and interpretation of the data;

Aleksandar Včev: participated in conception and design and in critical revision of the article;

Dunja Degmečić participated in conception and design of the study, in analysis and interpretation of the data and critical revision of the article and in drafting of the article.

\section{References}

1. Aktas S, Yesilcicek Calik K: Factors affecting depression during pregnancy and the correlation between social support and pregnancy depression. Iran Red Crescent Med J 2015; 17:e16640

2. Beck AT, Ward CH, Mendelson M, Mock J, Erbaugh J: An inventory for measuring depressiom. Arch Gen Psychiatry $1961 ; 6: 561-71$

3. Beck AT, Steer RA \& Brown GK: Manual for the Beck Depression Inventory-II. San Antonio.TX: Psychological Corporation, 1996

4. Beck AT, Steer RA: Beck Anxiety Inventory Manual. San Antonio: Harcourt Brace and Company, 1993

5. Beck AT, Epstein N, Brown G, Steer RA: An inventory for measuring clinical anxiety: Psychometric properties. Journal of Consulting and Clinical Psychology 1988, 56:893-897

6. Bergink V, Kooistra L, Lambregste-van den Berg MP, Wijnen H, Bunevicius $R$, van Baar A , Pop V: Validation of the Edinburg Depression Scale during pregnancy, Journal of Psychosomatic Research 2011; 70:385-389

7. Bodecs T, Horvath R, Kovacs I, Diffelne NM, Sandor J: Prevalence of depression and anxiety in early pregnancy on a population based Hungarian sample. Orv Hetil 2009; 150:1888-93

8. Bundevicius R, Kusminskas L, Bundevicius A, Nadisauskiene RJ, Jureniene K, Pop VJ: Psychosocial disk factors for depression during pregnancy. Acta Obstet Gynekol Scand 2009; 88:599-605

9. Choi SK, Park YG, Park IY, Ko HS, Shin JC: Impact of antenatal depression on perinatal outcomes and postpartum depression in Korean women. J Res Med Sci 2014; 19:807-812

10. Clark G: Discussing emotional health in pregnancy:the Edinburgh Postnatal Depresion Scale. Br J Community Nurs 2000; 5:91-8

11. Cox JL, Holden JM, Sagovsky R: Detection of postnatal depression. Development of the 10-item Edinburgh Postnatal Depression Scale. Brit J Psychiatry 1987; 150:782-786

12. Degmečić D: Womens mental health. Medicinska naklada, Zagreb 2014

13. Dmitrović-Kitanović B, Gojnić Dugalić M, Nikolić Baloski $G$, Dmitrović A, Soldatović I: Frequency of perinatal depression in Serbia and associated risk factors, Int J Soc Psychiatry September 2014; 60:528-532

14. Fazlagić A: Psychological correlates of postpartal depression. Acta Medica Medianae 2011; 50:62-68

15. Fonseca-Machado MO, Alves LC, Haas VJ, Monteiro JC, Gomes-Sponholz F: Under the shadow of maternity: pregnancy, suicidal ideation, and intimate partner violence. Rev Panam Salud Publica 2015; 37:258-64

16. Glavin K, Ellefsen B, Erdal B: Norwegian Public Health Nurses' Experience Using a Screening Protocol for Postpartum Depression. Public Health Nursing 2010; 27:255-62

17. Gluckman PD, Hanson MA, Cooper C, Thornburg KL: Effect of in utero and early-life con-ditions on adult health and disease. N Engl J Med 2008; 359:61-73

18. Jakovljević M: Depressive disorders: From early detection to succesful treatment. Pro Mente d.o.o., Zagreb, 2004

19. Kim JJ, LaPorte LM, Saleh MP, Allweiss S, Adams MG, Zhou Y, Silver RK: Suicide risk among perinatal women who report thoughts of self-harm on depression screens. Obstet Gynecol 2015; 125:885-93

20. Kozinszky Z, Dudas RB: Validation studies of the Edinburgh Postnatal Depression Scale for the antenatal period. Journal of Affective Disorders 2015; 176:95-105

21. Lancaster CA, Gold KJ, Flynn KA, Yoo H, Marcus SM, Davis MM: Risk factors for depressive symptoms during pregnancy: a systematic review. Am J Obstet Gynecol 2010; 202:5-14

22. Lindahl V, Pearson J, Colpe L: Prevalence of suicidality during pregnancy and the postpartum. Arch Womens Ment Health 2005; 8:77-87

23. Nakić-Radoš S, Herman R, Tadinac M: Is the Predictability of New-Onset Postpartum Depression Better During Pregnancy or in the Early Postpartum Period? A Prospective Study in Croatian Women, Health Care for Women International 2016; 7:23-44

24. Olivier JD, Akerud H, Sundstrom P: Antenatal depresion and antidepressants during pregnancy: unraveling the complex interactions for the offspring. Eur J Pharmacol $2015 ; 753: 257-62$ 
25. Park JH, Karmaus W, Zhang H: Prevalence and Risk Factors for Depressive Symptoms in Korean Women throughout Pregnancy and in Postpartum Period, Asian Nursing Research 2015; 9:219-225

26. Pearlstein T, Howard $M$, Salisbury A, Zlotnick C: Postpartum depression. Am J Obstet Gynecol 2009; 200:357-364

27. Peterson BD, Newton CR, Rosen KH, Skaggs GE: The relationship between coping and depression in men and women referred for in vitro fertilization. Fertil Steril 2006; 85:802-804

28. Varela P, Spyropoulou AC, Kalogerakis Z, Moraitou M, Zervas IM: Limited Depressive and Anxiety Symptoms Late in Pregnancy Are Not Related to Neonatal Outcomes, Nurs Midwifery Stud 2015; 4:e29308

29. Savitz DA, Stein CR, Ye F, Kellerman L, Silverman M: The epidemiology of hospitalized postpartum depression in New York State, 1995-2004. Ann Epidemiol 2011; 21:399-406
30. Screening for perinatal depression. Committee Opinion No. 630. American College of Obstetricians and Gynecologists. Obstet Gynecol 2015; 125:1268-71. 20.12.2015. http://www.acog.org/Womens-Health/Depression-andPostpartum-Depression

31. Slade P, Morrell CJ, Rigby A, Ricci K, Spittlehouse J, Brugha TS: Postnatal women's experiences of management of depressive symptoms: a qualitative study. $\mathrm{Br} J$ Gen Pract 2010; 60:440-448

32. Zhong $Q Y$, Gelaye B, Miller M, Fricchione GL Cai T, Johnson PA, Henderson DC, Williams MA: Suicidal behaviour-related hospitalisations among pregnant women in the USA, 2006-2012. Arch Womens Ment Health 2015; Dec 18 (Epub ahead of print)

33. Zubaran C, Foresti K, Verdi Schumach M, Amoretti AL, Rossi Thorell M, Muller LC: The Correlation Between Postpartum Depression and Health Status. Matern Child Health J 2010; 14:751-7

\section{Correspondence:}

Ass. Prof. Dunja Degmečić, $M D, P h D$

Faculty of Medicine, University Josip Juraj Strossmayer J. Huttlera 4, 31000 Osijek, Croatia

E-mail:ddegmecic@gmail.com 